\title{
An Investigation on Achieving Sustainability in Fused Deposition Modeling via Topology Optimization
}

\author{
https://doi.org/10.3991/ijes.v9i3.23595 \\ Andre Espach, Kapil Gupta ${ }^{(凶)}$ \\ University of Johannesburg, Johannesburg, Republic of South Africa \\ kgupta@uj.ac.za
}

\begin{abstract}
Fused deposition modeling (FDM) is one of the important additive layer manufacturing techniques, used to fabricate products from heated polymer materials. Like other manufacturing processes, sustainability interventions are desirable in FDM to attain energy and resource efficiency simultaneously with good product quality. This paper reports the results of investigation conducted by the authors on effect of topology optimization strategy on quality of FDM parts and sustainability of the process. A total of eighteen experiments have been conducted by varying infill pattern and density at three levels each for optimized and unoptimized topology, based on Taguchi L18 technique. Statistical fitness of the data has been insured by ANOVA. Both infill density and pattern have been found the significant parameters. Better mechanical strength has been obtained for topology optimized FDM parts. A set of confirmation experiments have been conducted followed by quantification of sustainability and indicated that improved mechanical properties simultaneously with enhanced sustainability can be achieved via topology optimization in FDM process.
\end{abstract}

Keywords - additive manufacturing, FDM, topology optimization, sustainability

\section{$1 \quad$ Introduction}

In last few years, there has been an accelerated growth in demand of additive manufacturing (AM) techniques due to their advantages over conventional manufacturing. Fused deposition modelling (FDM) is an important AM based technique where products are manufactured layer by layer through an extruder from heated polymer materials [1-3]. It has widespread applications from prototype manufacturing to rapid tool making. Low material consumption and waste, ease of fabrication of complex geometry parts, and environment-friendliness etc. are some of the significant benefits offered by FDM $[4,5]$. The exponential increase in FDM application during recent years is justifying further and more in-depth research into sustainability. The life cycle perspective of any type of manufacturing technology needs to be understood when sustainability is a topic of the research. Life cycle assessment is a comprehensive and systematic evaluation approach, covering the entire life cycle of a product from the early stages of manufacture through final product implementation and in some cases, 
maintenance. FDM offers a simplified manufacturing-impacts phase which is divided into three stages: filament production, FDM manufacturing, and post-processing [6]. Figure 1 shows three dimensions used for analyzing the sustainability performance of a FDM manufactured part [5]. In FDM process, electrical energy is consumed, converted into thermal and mechanical energy, and lost as heat. The primary material is the material that is present in the final product, support and binding material is referred to as auxiliary material. The recycling of auxiliary material is a growing fiend in sustainable $\mathrm{AM}$ and some technologies offer to user the ability to convert waste into functional filament.

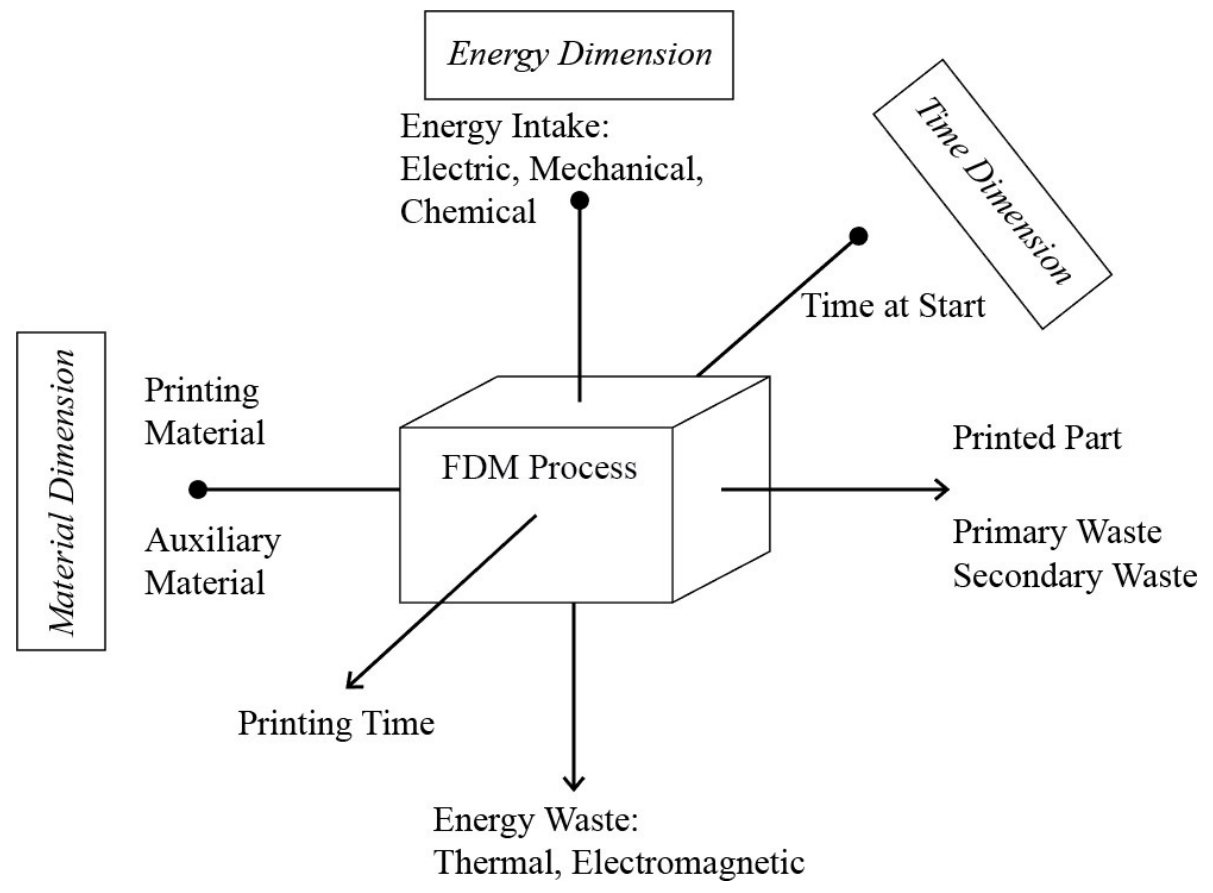

Fig. 1. Three sustainability analysis dimensions

Quality of fabricated parts and process performance and sustainability are major indicators for manufacturability. In additive manufacturing too, attempts have been made to enhance product quality along with achieving sustainability. Resource and energy consumption that include, material consumption, manufacturing time, and energy consumption, are the main sustainability indicators. FDM products which are to be used in structural applications, should possess good mechanical strength, or equipped with high load bearing capability. The optimization of total material distribution during fabrication is needed for that. It can be achieved via topology optimization by which optimal placement of a given material is done. It is interesting to study the effect of this topology optimization on strength as well as on sustainability indicators. Topology optimization involves reducing material weight by the addition of hollow voids in the part's internal infill structure [6]. Infill pattern (the repeating pattern with which filament is extruded to fabricate parts in FDM) and the density of this pattern are 
also important parameters when topology optimization effects need to be investigated. Topology optimization as a product design tool or technique can only be utilized to its full potential when the technique is able to take anisotropic properties into account. Depending on the application, a stiffness-based topology optimization algorithm may be applied to FDM manufactured parts and still yield acceptable results.

\section{Literature review}

Belter and Dollar [7] successfully conducted research on increasing the strength of thermoplastic printed parts by filling compositing technique. Careful placement of voids and their filling with high-strength resins were the key factors behind the success of their work. In an interesting study, a density-based topology optimization method was used [8]. The results were referred as inputs for shape optimization of parts to be fabricated and standardization of additive manufacturing process. Optimization of strength for anisotropic material by sensitivity analysis based on Tsai-Wu criteria was done with numerical and experimental validation by a group of researchers [9]. Zhang et al. [10] conducted a novel work in which they successfully developed lightweight structure of 3D object capable to withstand external loads from various directions, by optimizing the topology and volume of the structure.

Some literature based on past work conducted in the area of sustainability in additive manufacturing and FDM, was also reviewed. It is found that FDM utilizes larger layer heights than other AM technologies [4], reduction of layer height, build orientation and surface angles would simply result in better surface roughness [11], increase in layer thickness greatly influences the energy consumption, and support material optimization is required to reduce material waste [12]. A detailed electrical energy consumption analysis was conducted by Peng [5] in 3D printing. The research focused on identifying the major electrical energy consumers of a desktop 3D printer and analyzing the electrical energy consumed during printing process. It is evident from the results reported by him that the major electrical energy consumers are heating bed, extruder hot-end, and stepper motor assembly. Layer height was identified as the most influential factor for electrical energy consumption. Reduction in infill density minimizes energy consumption but at a compromise with mechanical performance.

A review of the important available literature reveals that extremely limited research has been conducted on effect of topology optimization in FDM and its consequences towards sustainability. The effect or consequence of application of topology optimization in FDM parts on material and electrical energy consumption, and manufacturing time is still to be focused upon and evaluated. In addition to that the implications of topology optimization on mechanical performance of parts and sustainability of the FDM process, is required to be investigated.

The present research work focuses on implementing topology optimization in FDM manufacturing to obtain mechanically strong parts at reduced cost (material and electrical energy consumption). When comparing traditional manufacturing techniques to additive manufacturing, it is perceived that the latter will offer better performance in terms of sustainability. Little research is done on quantifying some of the most common sustainability performance indicators. The present work will quantify and analyze the 
effects of topology optimization on mechanical strength of fabricated part, and material and energy consumption, and manufacturing time.

\section{Experimental methodology}

A total of eighteen experiments designed based on Taguchi $\mathrm{L}_{18}$ robust technique have been conducted [13]. The G-code for both sets is generated in Prusa's slicer then copied to the 3D printer (Creality CR-10) where is has been executed. Table 1 shows the details of input parameters and specification of FDM machine used in the present work. The manufactured specimens resemble a simple rectangular beam with having $200 \mathrm{~mm}$ length, $20 \mathrm{~mm}$ width, and $15 \mathrm{~mm}$ height. The specimen has a notch on the top face in the centre of the beam as a designated failure area.

Table 1. Details of FDM parameters and machine specification

\begin{tabular}{|c|c|c|c|c|c|}
\hline \multirow{2}{*}{ Variable Parameters } & \multirow{2}{*}{ Unit } & \multicolumn{3}{|c|}{ Level } & \multirow{2}{*}{ Fixed Parameters } \\
\hline & & L1 & L2 & L3 & \\
\hline $\begin{array}{l}\text { Topologically optimized } \\
\text { (Either optimized or not) }\end{array}$ & Categorical & Unoptimized & Optimized & - & \multirow{3}{*}{$\begin{array}{l}\text { Material (PLA), } \\
\text { printing temperature } \\
\left(225^{\circ} \mathrm{C}\right) \text {, perimeters } \\
(2), \text { layer height } \\
(0.25 \mathrm{~mm})\end{array}$} \\
\hline Infill density & $\%$ & 15 & 30 & 45 & \\
\hline Infill pattern & Categorical & Triangle & Honeycomb & Cubic & \\
\hline \multicolumn{6}{|c|}{$\begin{array}{l}\text { Specification of FDM machine: } \\
\text { Build plate: } 300 \mathrm{~mm} \times 300 \mathrm{~mm} \times 400 \mathrm{~mm} \\
\text { Printing temperatures: Build plate- } 50^{\circ} \mathrm{C} \text {, Extruder Hot end- } 225^{\circ} \mathrm{C} \\
\text { Printing speed: Layers- } 80 \mathrm{~mm} / \mathrm{s} \text {, Infill- } 60 \mathrm{~mm} / \mathrm{s} \text {, Perimeters- } 80 \mathrm{~mm} / \mathrm{s} \text {, Solid- } 40 \mathrm{~mm} / \mathrm{s}\end{array}$} \\
\hline
\end{tabular}

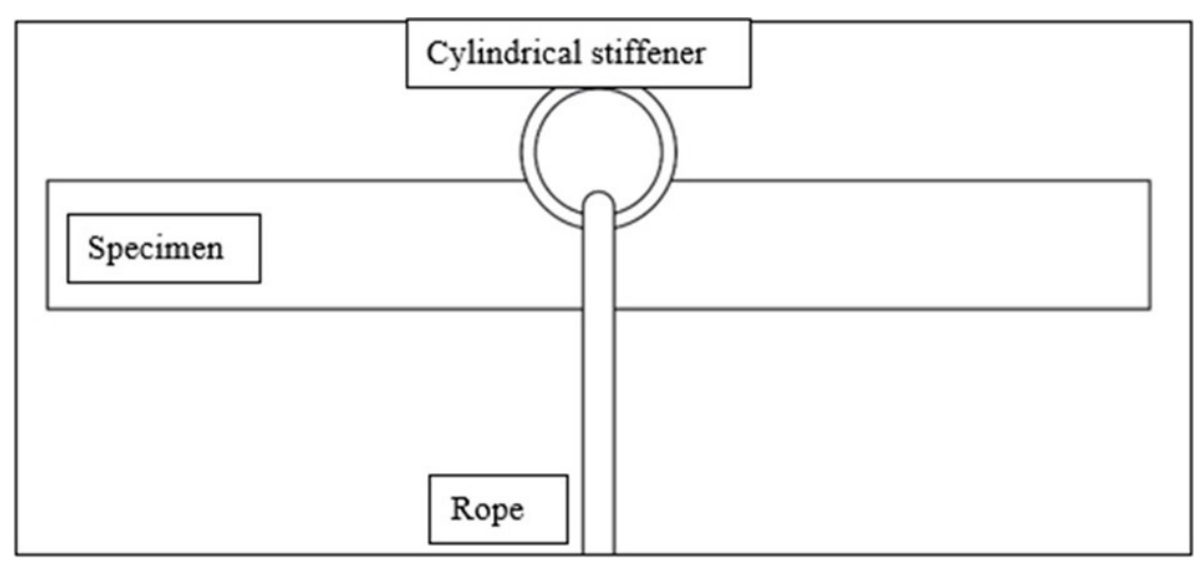

Fig. 2. Test specimen detail

All 18 specimens were tested individually. Each specimen was mounted to a ridged frame. A cylindrical piece of metal was placed in the notch of the specimen, where the load is applied, as illustrated in Figure 2. This is done to minimize localized stress concentrations that may result from the rope 'cutting' into the specimen. The rope 
attaches to a bucket that holds the weight. The weight in the bucket is gradually increased until the specimen fails. The weight is recorded using a calibrated hanging scale (Mini Crane Scale - Model No. MNCS-M). All manufacturing details (manufacturing time and material consumptions) is taken directly from the slicer and recorded. Figure 3 shows the build plate setup along with the slicer settings used to 3D print the non-optimized geometries. Figure 4 shows the FDM machine that was used to produce all experimental specimens in the present work.

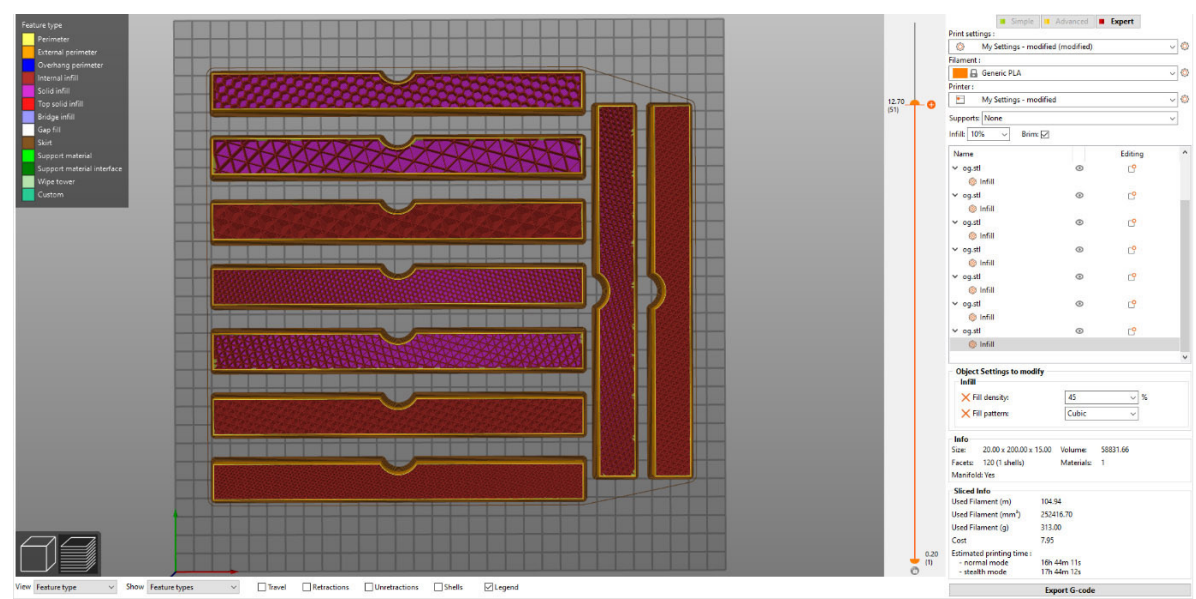

Fig. 3. Slicer output display

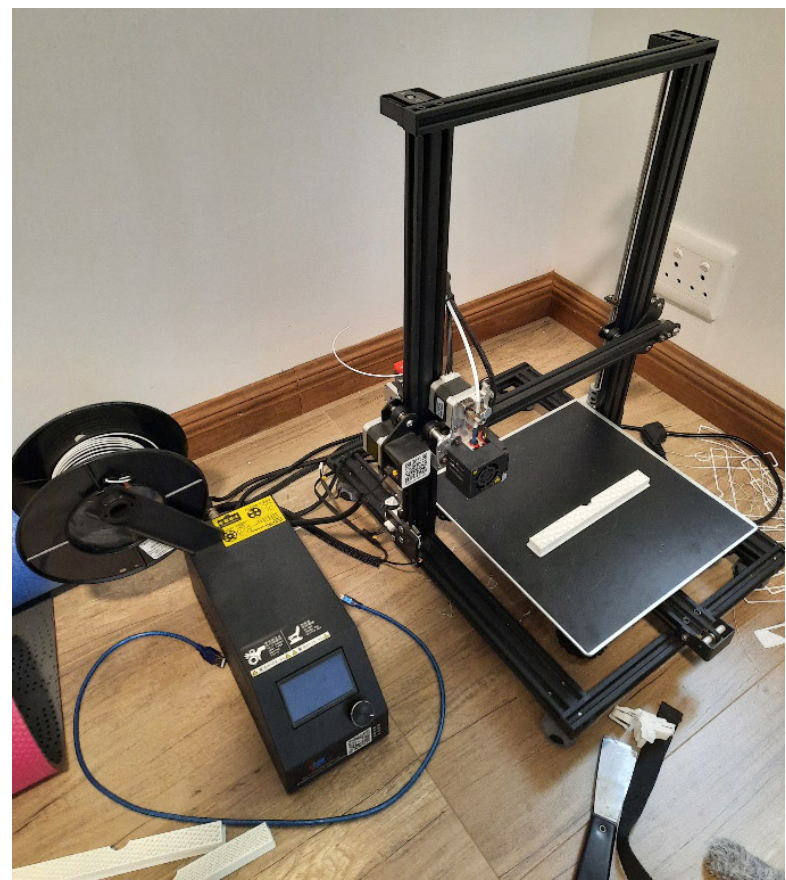

Fig. 4. FDM machine (model: Creality CR 10) used in the present work 


\section{$4 \quad$ Results and discussion}

Table 2 presents the values of mean mechanical/structural strength, material consumption, manufacturing time and electrical energy consumption corresponding to eighteen runs of experiments. The mixed-level Taguchi design allows for an in-depth comparative study between the optimized and non-optimized specimens.

Table 2. Experimental results

\begin{tabular}{|c|c|c|c|c|c|c|c|c|c|}
\hline \multirow{3}{*}{$\begin{array}{l}\text { Exp } \\
\text { No. }\end{array}$} & \multicolumn{3}{|c|}{ Input Parameters } & \multicolumn{6}{|c|}{ Responses } \\
\hline & \multirow{2}{*}{$\begin{array}{c}\text { Topology } \\
\text { Optimized }\end{array}$} & \multirow{2}{*}{$\begin{array}{c}\text { Infill } \\
\text { Density }\end{array}$} & \multirow{2}{*}{$\begin{array}{c}\text { Infill } \\
\text { Pattern }\end{array}$} & \multicolumn{3}{|c|}{$\begin{array}{c}\text { Structural } \\
\text { Strength [kg] }\end{array}$} & \multirow{2}{*}{\begin{tabular}{|c|}
$\begin{array}{c}\text { Material } \\
\text { Consumption } \\
{[\mathrm{g}]}\end{array}$ \\
Avg. \\
\end{tabular}} & \multirow{2}{*}{$\begin{array}{c}\text { Manufacturing } \\
\text { Time [s] }\end{array}$} & \multirow{2}{*}{$\begin{array}{c}\begin{array}{c}\text { Electrical } \\
\text { Energy } \\
\text { Consumption } \\
\text { [Wh] }\end{array} \\
\text { Avg. }\end{array}$} \\
\hline & & & & $\mathbf{R}_{1}$ & $\mathbf{R}_{2}$ & Avg. & & & \\
\hline 1 & No & $15 \%$ & Triangular & 39.21 & 41.21 & 40.21 & 23.54 & 3908 & 207.1 \\
\hline 2 & No & $15 \%$ & Honeycomb & 43.00 & 43.28 & 43.14 & 24.84 & 5348 & 290.85 \\
\hline 3 & No & $15 \%$ & Cubic & 44.00 & 47.66 & 45.33 & 23.53 & 3909 & 211.13 \\
\hline 4 & No & $30 \%$ & Triangular & 39.7 & 40.6 & 43.45 & 32.81 & 5098 & 276.41 \\
\hline 5 & No & $30 \%$ & Honeycomb & 44.3 & 46.3 & 45.00 & 35.54 & 9019 & 487.13 \\
\hline 6 & No & $30 \%$ & Cubic & 47 & 49 & 48.00 & 32.81 & 5150 & 278.16 \\
\hline 7 & No & $45 \%$ & Triangular & 40 & 41 & 40.5 & 42.12 & 6313 & 338.23 \\
\hline 8 & No & $45 \%$ & Honeycomb & 55 & 55 & 55.00 & 45.50 & 12987 & 706.45 \\
\hline 9 & No & $45 \%$ & Cubic & 54.75 & 55.5 & 55.25 & 42.07 & 6327 & 341.73 \\
\hline 10 & Yes & $15 \%$ & Triangular & 42 & 44 & 43.00 & 25.91 & 4140 & 221.61 \\
\hline 11 & Yes & $15 \%$ & Honeycomb & 53.10 & 52.80 & 52.90 & 24.26 & 5585 & 300.9 \\
\hline 12 & Yes & $15 \%$ & Cubic & 53 & 54.2 & 53.60 & 25.93 & 5086 & 274.7 \\
\hline 13 & Yes & $30 \%$ & Triangular & 50 & 49.20 & 49.60 & 29.79 & 6007 & 320.44 \\
\hline 14 & Yes & $30 \%$ & Honeycomb & 56 & 53.20 & 54.60 & 28.70 & 7414 & 400.43 \\
\hline 15 & Yes & $30 \%$ & Cubic & 56.4 & 56.60 & 56.50 & 30.05 & 6054 & 326.98 \\
\hline 16 & Yes & $45 \%$ & Triangular & 49 & 50 & 55 & 34.02 & 6890 & 372.1 \\
\hline 17 & Yes & $45 \%$ & Honeycomb & 61.6 & 65.4 & 63.50 & 32.72 & 9271 & 500.74 \\
\hline 18 & Yes & $45 \%$ & Cubic & 63.5 & 64.70 & 64.10 & 33.99 & 6936 & 374.62 \\
\hline
\end{tabular}

\subsection{Analysis of mechanical strength}

Table 3 presents ANOVA results for mechanical strength. In ANOVA, the p i.e., probability values show the level of significance of each factor. Lower p values indicate that the factor values have higher probability of falling within the ranges which mostly impact the outcome of the experiment. As shown in Table 3, the p-value for topology optimization is 0.000 which indicates that the topology optimization contributes to the structural strength of the part. Also shown is that infill density and infill pattern greatly affect the mechanical strength, which was expected from literature studies. Similarly, for the F-ratio, topology optimization is a significant term. It is evident that topology 
optimization contributes more to mechanical strength than the infill pattern. Moreover, the R-squared value $91.68 \%$ for established model is close to 1 which confirms that the generated model is statistically significant. For the mechanical strength response variable, larger is better type quality attribute was selected. The main effects plots for mean mechanical strength are shown in Figure 5.

Table 3. ANOVA results for mechanical strength

\begin{tabular}{|l|c|c|c|c|c|c|}
\hline \multicolumn{1}{|c|}{ Source } & $\begin{array}{c}\text { Degrees of } \\
\text { Freedom }\end{array}$ & $\begin{array}{c}\text { Sum of } \\
\text { Square }\end{array}$ & $\begin{array}{c}\text { Mean } \\
\text { Square }\end{array}$ & F-ratio & P-Value & $\begin{array}{c}\text { Percentage } \\
\text { Contribution (\%) }\end{array}$ \\
\hline $\begin{array}{l}\text { Topology } \\
\text { optimization }\end{array}$ & 1 & 328.7 & 328.7 & 51.83 & 0.000 & 56.29 \\
\hline Infill density & 2 & 261.89 & 130.95 & 20.65 & 0.000 & 22.43 \\
\hline Infill pattern & 2 & 248.54 & 124.27 & 19.59 & 0.000 & 21.28 \\
\hline Error & 12 & 76.1 & 6.342 & & & \\
\hline Total & 17 & 915.24 & & & & \\
\hline
\end{tabular}

The implementation of topology optimization as a design alteration resulted in an increase in structural strength. It is evident that increase in infill density increases the structural strength, a direct proportional relationship exists between two, as was confirmed in literature $[14,15]$. It is also evident that the triangular infill pattern is the 'weakest' infill pattern of the three, due to the lowest value of mechanical strength $(40.21 \mathrm{~kg})$, and cubic is the 'strongest', as the highest mechanical strength $(64.1 \mathrm{~kg})$ has been obtained using cubic infill. The effect of topology optimization on structural strength can be explained as follows: the overall infill density determines the average density of the part, decreasing the part volume whilst maintaining the infill density (as a $\%$ value) will result in a higher localized density. This increase in mass in topologically crucial areas led to the increase in structural strength.

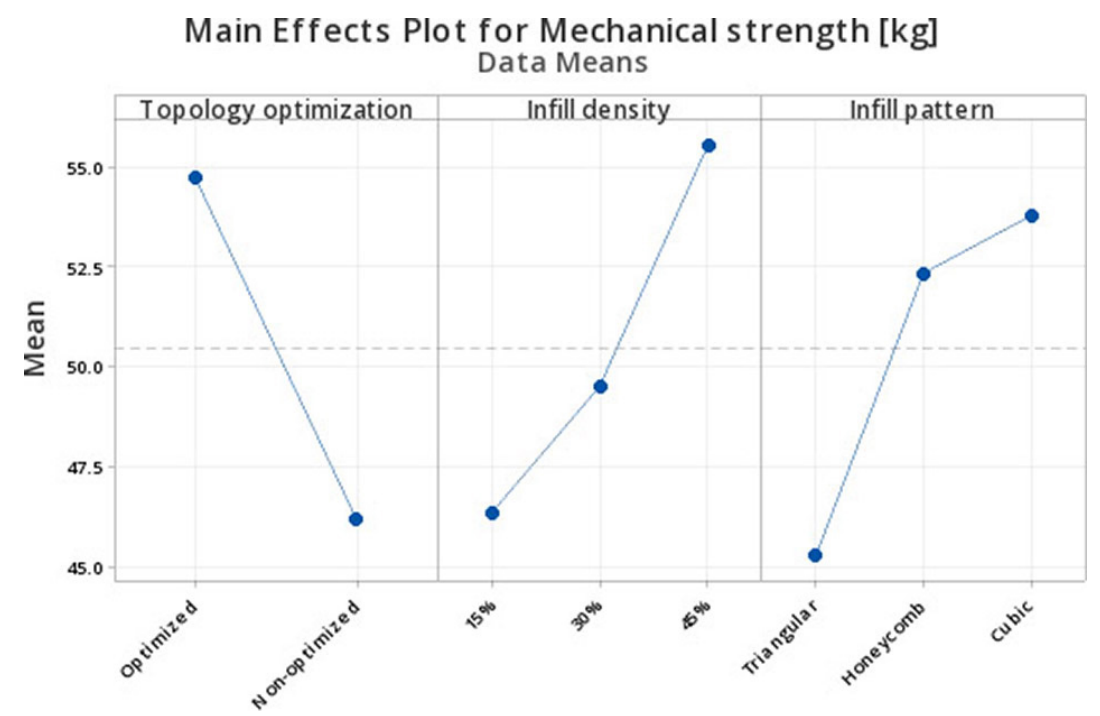

Fig. 5. Main effect plots for mechanical strength 


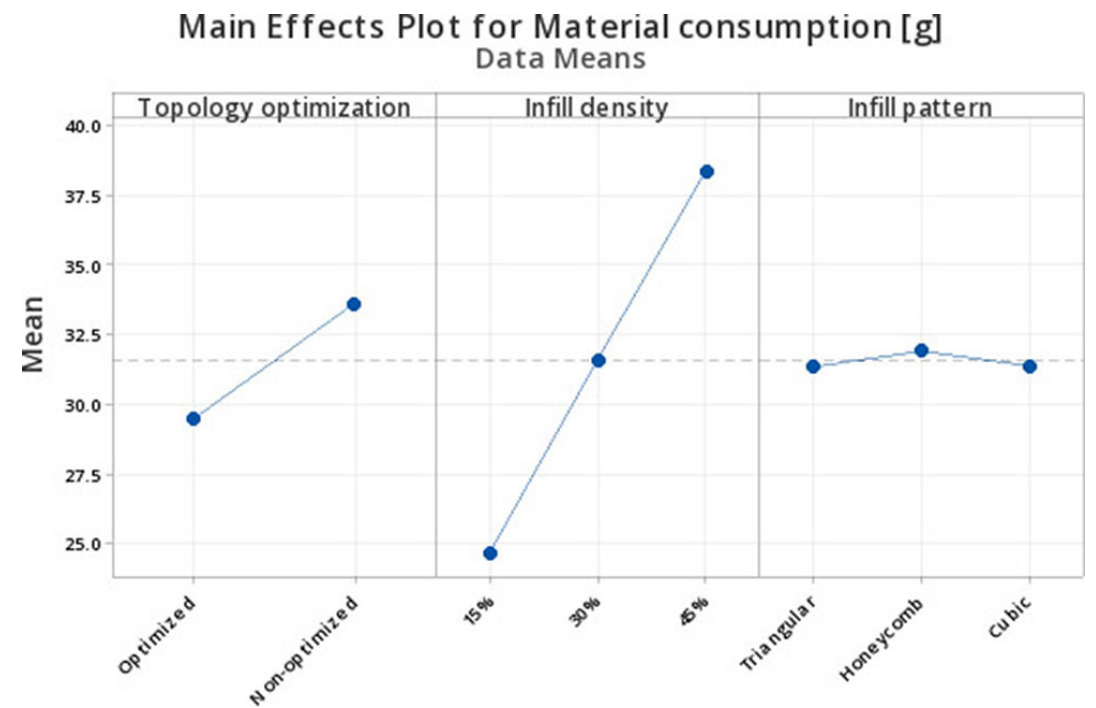

Fig. 6. Main effect plots for material consumption

\subsection{Analysis of material consumption}

The main effects plots for material consumption are shown in Figure 6. It depicts that the mean of the material consumption in grams for each variation of the input parameters. The mean material consumption of the topology optimized parts is less than the non-optimized parts. The growth in material consumption seems linear for the infill density and is shown to increase as the infill density increases. The honeycomb infill pattern showed is the least conservative in amount of material consumed.

Table 4 presents ANOVA results for the material consumption in the main experiments. The p-value and F-ratio of topology optimization indicate that it does affect the material consumption. As expected, the infill pattern does not affect the material consumption much as, it is merely the pattern and does not affect the quantity in any substantial way. The infill density does affect the material consumption as the infill density relates to the overall mass in the part. For material consumption response variable, smaller is better, type quality attribute has been considered.

Table 4. ANOVA results for material consumption

\begin{tabular}{|l|c|c|c|c|c|c|}
\hline \multicolumn{1}{|c|}{ Source } & $\begin{array}{c}\text { Degrees of } \\
\text { Freedom }\end{array}$ & $\begin{array}{c}\text { Sum of } \\
\text { Square }\end{array}$ & $\begin{array}{c}\text { Mean } \\
\text { Square }\end{array}$ & F-ratio & P-Value & $\begin{array}{c}\text { Percentage } \\
\text { Contribution } \\
\text { (\%) }\end{array}$ \\
\hline $\begin{array}{l}\text { Topology } \\
\text { optimization }\end{array}$ & 1 & 77.667 & 77.667 & 8.61 & 0.012 & 20.98 \\
\hline Infill density & 2 & 565.977 & 282.988 & 31.39 & 0.000 & 76.43 \\
\hline Infill pattern & 2 & 1.195 & 0.597 & 0.07 & 0.936 & 0.16 \\
\hline Error & 12 & 108.187 & 9.016 & & & \\
\hline Total & 17 & 753.026 & & & & \\
\hline & \multicolumn{7}{|c|}{ R-Squared=85.63\% } & & \\
\hline
\end{tabular}




\subsection{Analysis of manufacturing time}

Table 5 presents ANOVA results for manufacturing time. For this response, the topology optimization contributed the least to manufacturing time $(9.13 \%)$. This is because there is an increase in the total length of external perimeters due to the change in geometry for the optimized specimens. When topology optimization is used, the overall volume of the part is expected to decrease. This in turn results in possible cavities within the design. These cavities will need to be closed to obtain a geometrically acceptable and functional part. These cavities will be manufactured with the same perimeter count as the rest of the part. The additional perimeters will result in an increase in manufacturing time. For the manufacturing time response variable, smaller is better type quality attribute has been considered.

Figure 7 shows that the infill density and infill pattern affect the manufacturing time far more than the application of topology optimization. Honeycomb is the least conservative and resulted in the highest manufacturing time. There also seems to exist a directly proportional relationship between infill density and manufacturing time with $45 \%$ infill density requiring almost double the time compared to $15 \%$ infill density.

Table 5. ANOVA results for manufacturing time

\begin{tabular}{|l|c|c|c|c|c|c|}
\hline \multicolumn{1}{|c|}{ Source } & $\begin{array}{c}\text { Degrees of } \\
\text { Freedom }\end{array}$ & $\begin{array}{c}\text { Sum of } \\
\text { Square }\end{array}$ & $\begin{array}{c}\text { Mean } \\
\text { Square }\end{array}$ & F-ratio & P-Value & $\begin{array}{c}\text { Percentage } \\
\text { Contribution (\%) }\end{array}$ \\
\hline $\begin{array}{l}\text { Topology } \\
\text { optimization }\end{array}$ & 1 & 25,388 & 25,388 & 0.02 & 0.897 & 9.13 \\
\hline Infill density & 2 & $35,890,366$ & $17,945,183$ & 12.27 & 0.001 & 45.22 \\
\hline Infill pattern & 2 & $31,145,406$ & $15,572,703$ & 10.65 & 0.002 & 42.36 \\
\hline Error & 12 & $17,546,587$ & $1,462,216$ & & & \\
\hline Total & 17 & $84,607,746$ & & & & \\
\hline \multicolumn{7}{|c|}{ R-Squared=79.26\% } \\
\hline
\end{tabular}

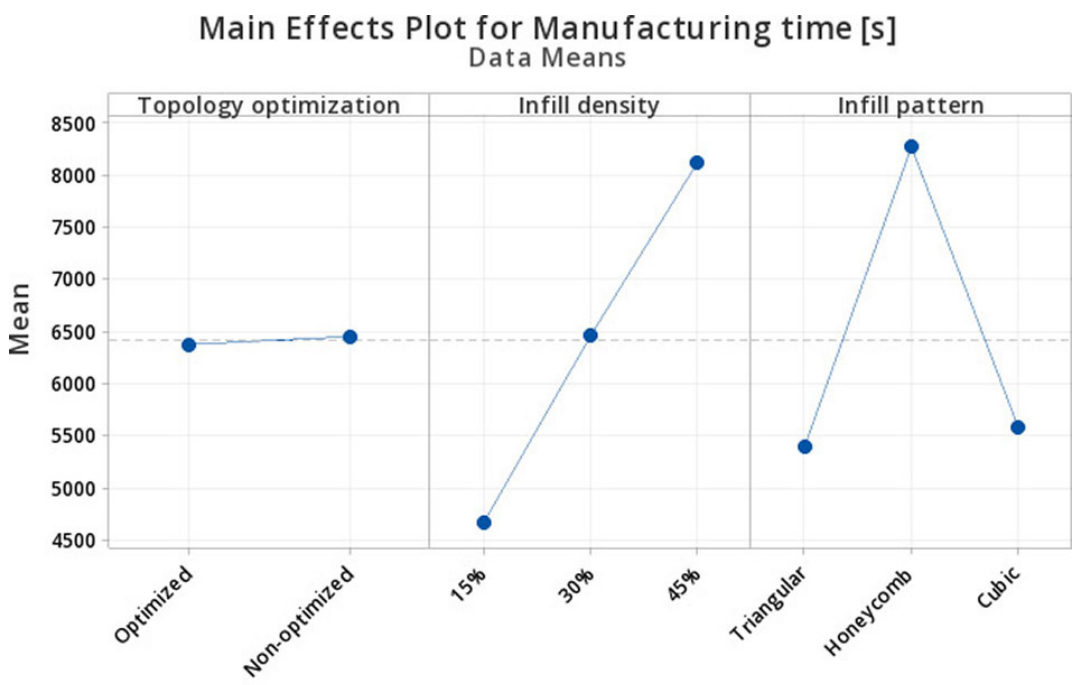

Axis Label

Fig. 7. Main effect plots for manufacturing time 


\subsection{Analysis of electrical energy consumption}

Table 6 shows the ANOVA results for electrical energy consumption in watt-hours. From the results, it is seen that the infill density contributes to the electrical energy consumption more than any of the other input variables. It is also interesting to note that the R-squared value is remarkably similar to that of manufacturing time given in Table 5, and adds merit to the literature review's finding that manufacturing time and electrical energy consumption relate almost linearly.

Table 6. ANOVA results for electrical energy consumption

\begin{tabular}{|l|c|c|c|c|c|c|}
\hline \multicolumn{1}{|c|}{ Source } & $\begin{array}{c}\text { Degrees of } \\
\text { Freedom }\end{array}$ & $\begin{array}{c}\text { Sum of } \\
\text { Square }\end{array}$ & $\begin{array}{c}\text { Mean } \\
\text { Square }\end{array}$ & F-ratio & P-Value & $\begin{array}{c}\text { Percentage } \\
\text { Contribution (\%) }\end{array}$ \\
\hline $\begin{array}{l}\text { Topology } \\
\text { optimization }\end{array}$ & 1 & 111 & 110.9 & 0.03 & 0.876 & 0.131 \\
\hline Infill density & 2 & 105,995 & $52,997.6$ & 12.14 & 0.001 & 53.08 \\
\hline Infill pattern & 2 & 93,429 & $46,714.4$ & 10.70 & 0.002 & 46.79 \\
\hline Error & 12 & 52,368 & 4,364 & & & \\
\hline Total & 17 & 251,903 & & & & \\
\hline \multicolumn{7}{|c|}{ R-Squared=79.21\% } \\
\hline
\end{tabular}

Main Effects Plot for Energy consumption [Wh] Data Means

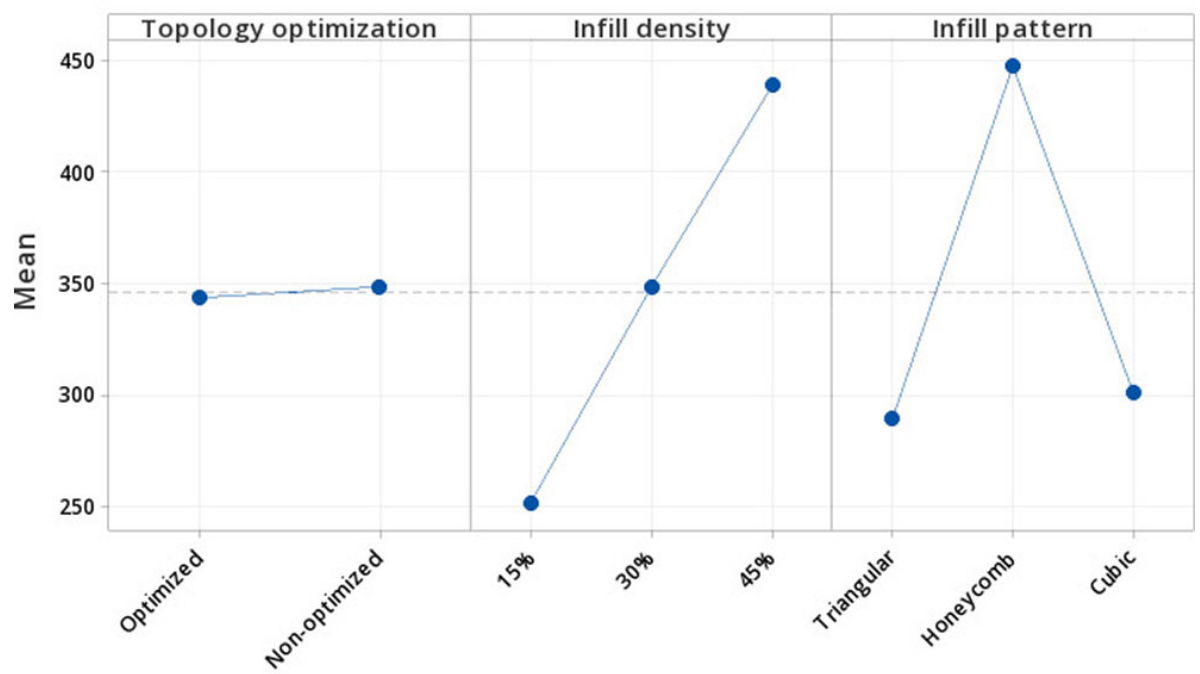

Axis Label

Fig. 8. Main effect plots for electrical energy consumption

For electrical energy consumption, a smaller is better type quality attribute is considered. Figure 8 shows the main effects plot for electrical energy consumption in watthours. From the results the infill density and infill pattern affect the electrical energy 
consumption more than topology optimization. The topology optimized parts' mean is slightly lower than the non-optimized parts.

Components responsible for heating has the highest electrical demand and consumes the most electrical energy. The heating bed and extruder hot end needs to heat up to a certain temperature for the manufacturing process to operate ideally. The electrical energy consumption for the heating components is inversely proportional to the external temperatures of the machine [10]. Thermally isolating the FDM machine will greatly reduce the electrical energy consumption.

The heating components of the FDM machine can be simplified as resistance loads, which means that the electrical energy savings is easily calculated if the power ratings and manufacturing time is known. A $10 \%$ saving on manufacturing time will result in roughly $10 \%$ savings in electrical energy costs. Therefor manufacturing time reduction will contribute greatly to the profitability of FDM manufacturing processes.

Figure 9 shows the current draw vs time for the FDM machine. Three sections are visible where the current draw goes above 1 Amp. The current draw goes above $1 \mathrm{amp}$ for 5 seconds at a time. This current draw is associated with the heating bed switching on and off during manufacturing time. Using the electrical energy consumption trends in the data, a simple electrical energy cost saving can be estimated.

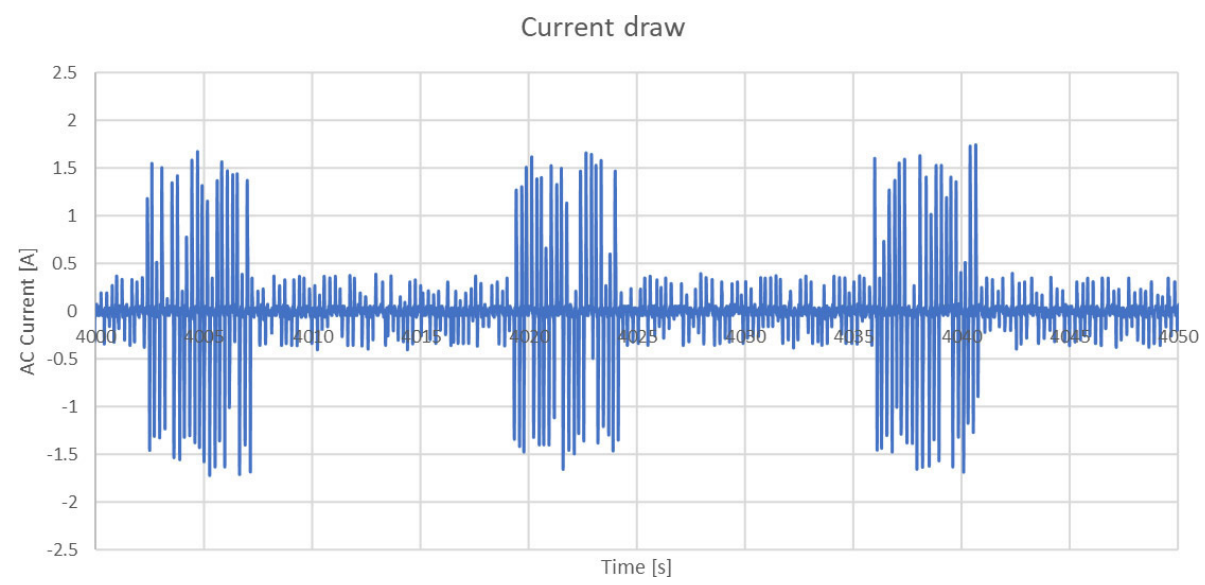

Fig. 9. FDM machine current draw

From Table 7, it is evident that the electrical energy consumption increased for the optimized infill. This is expected as the manufacturing time increased for the optimized specimen. The percentage increase is tabulated in Table 8 . From the data, the increase in electrical energy consumption seems to decrease as the infill density is increased. Table 9 shows the increase in mechanical strength that is gained from optimizing the topology of the specimen for the specific loading conditions. The increase in mechanical strength also decreases as the infill density increases. This is logical as the optimized topology cannot continue to increase the mechanical strength when the density is $100 \%$. At best, the mechanical strength will be equal for optimized vs non-optimized topology, although very unlikely. 
Table 7. Total electrical energy consumption at optimized and non-optimized infill

\begin{tabular}{|l|c|c|c|c|c|c|}
\hline & $\begin{array}{c}\mathbf{1 5 \%} \text { Non- } \\
\text { Optimized } \\
\text { Infill }\end{array}$ & $\begin{array}{c}\mathbf{1 5 \%} \\
\text { Optimized } \\
\text { Infill }\end{array}$ & $\begin{array}{c}\mathbf{3 0 \%} \text { Non- } \\
\text { Optimized } \\
\text { Infill }\end{array}$ & $\begin{array}{c}\mathbf{3 0 \%} \\
\text { Optimized } \\
\text { Infill }\end{array}$ & $\begin{array}{c}\mathbf{4 5 \%} \text { Non- } \\
\text { Optimized } \\
\text { Infill }\end{array}$ & $\begin{array}{c}\mathbf{4 5 \%} \\
\text { Optimized } \\
\text { Infill }\end{array}$ \\
\hline $\begin{array}{l}\text { Total } \\
\text { consumption } \\
\text { [Wh] }\end{array}$ & 211.13 & 274.7 & 278.16 & 326.98 & 341.73 & 374.62 \\
\hline
\end{tabular}

Table 8. Percentage increase in electrical energy consumption for optimized infills

\begin{tabular}{|l|c|c|c|}
\hline & $\mathbf{1 5 \%}$ Infill & $\mathbf{3 0 \%}$ Infill & $\mathbf{4 5 \%}$ Infill \\
\hline $\begin{array}{l}\text { Electrical energy consumption } \\
\text { increase [\%] }\end{array}$ & 30.1 & 17.55 & 9.62 \\
\hline
\end{tabular}

Table 9. Increase in mechanical strength due to topology optimized infill

\begin{tabular}{|l|c|c|c|}
\hline & $\mathbf{1 5 \%}$ Infill & $\mathbf{3 0 \%}$ Infill & $\mathbf{4 5 \%}$ Infill \\
\hline $\begin{array}{l}\text { Increase in mechanical } \\
\text { strength [\%] }\end{array}$ & 18.24 & 17.71 & 16.02 \\
\hline
\end{tabular}

Percentage increases vs Infill density

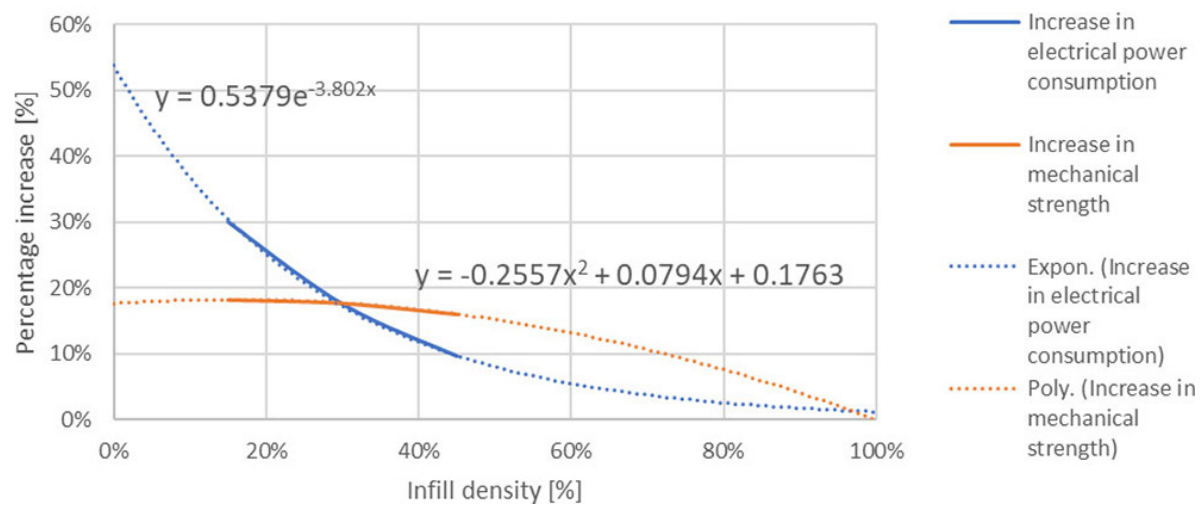

Fig. 10. Effect of infill density of topology optimized specimens on the percentage increase in electrical energy consumption and mechanical strength

A positive electrical energy cost saving can be expected when the percentage increase in mechanical strength is larger than the percentage increase in electrical energy consumption. Figure 10 shows that topology optimization will result in electrical energy cost savings at $28 \%$ infill density. The maximum expected electrical energy cost savings is at $61 \%$ infill density. 


\subsection{Confirmation experiments}

To validate the statement in the previous section that topology optimization will result in improved sustainability performance for a range of infill densities, confirmation experiments are conducted. Three infill densities are chosen to conduct confirmation experiments with to test the robustness of the mathematical models shown in Figure 10.

Table 10 shows the results for the confirmation experiments. A table of percentage increase i.e., Table 11 is based on the data from Tables 9 and 10 to check the accuracy of the mathematical model in Figure 10.

Table 10. Confirmation experiment results

\begin{tabular}{|l|c|c|c|c|c|}
\hline \multicolumn{2}{|c|}{ Input Variables } & \multicolumn{4}{c|}{ Response Variables } \\
\hline $\begin{array}{c}\text { Topology } \\
\text { Optimized }\end{array}$ & $\begin{array}{c}\text { Infill } \\
\text { Density } \\
{[\%]}\end{array}$ & $\begin{array}{c}\text { Mechanical } \\
\text { Strength } \\
{[\mathbf{k g}]}\end{array}$ & $\begin{array}{c}\text { Material } \\
\text { Consumption } \\
{[\mathbf{g}]}\end{array}$ & $\begin{array}{c}\text { Manufacturing } \\
\text { Time } \\
{[\mathbf{s}]}\end{array}$ & $\begin{array}{c}\text { Electrical Energy } \\
\text { Consumption } \\
{[\mathbf{W h}]}\end{array}$ \\
\hline Yes & 25 & 54.25 & 30.6 & 5532 & 304.26 \\
\hline Yes & 40 & 62.3 & 32 & 6324 & 341.1 \\
\hline Yes & 55 & 71.16 & 36.2 & 7742 & 408.62 \\
\hline No & 25 & 44.48 & 32.96 & 4259 & 237.3 \\
\hline No & 40 & 52.33 & 37.44 & 5565 & 300.17 \\
\hline No & 55 & 60.49 & 45.61 & 7200 & 380.01 \\
\hline
\end{tabular}

Table 11 shows the percentage increase in response variables for the confirmation experiments. Positive difference means that the optimized geometry yielded a larger result than the non-optimized part. The increase in mechanical strength is highest at $25 \%$ infill density for the optimized specimen. As the infill density increases, the effects of topology optimization on the specimens become more and more apparent.

Table 11. Confirmation experiments and percentage increase in responses

\begin{tabular}{|c|c|c|c|c|}
\hline \multirow{2}{*}{$\begin{array}{c}\text { Infill } \\
\text { Density }\end{array}$} & \multicolumn{4}{|c|}{ Percentage increase in response variables [\%] } \\
\cline { 2 - 5 } & $\begin{array}{c}\text { Mechanical } \\
\text { Strength [\%] }\end{array}$ & $\begin{array}{c}\text { Material } \\
\text { Consumption [\%] }\end{array}$ & $\begin{array}{c}\text { Manufacturing } \\
\text { Time [s] }\end{array}$ & $\begin{array}{c}\text { Electrical Energy } \\
\text { Consumption [Wh] }\end{array}$ \\
\hline $25 \%$ & 21.9 & -7.1 & 29.6 & 28.27 \\
\hline $40 \%$ & 19 & -14.5 & 13.6 & 13.7 \\
\hline $55 \%$ & 16 & -20.6 & 7.5 & 7.36 \\
\hline
\end{tabular}

To benefit from the results in the present work, the user will need to work with an infill density range between $28 \%$ and $95 \%$.

Quantification of sustainability enhancement. To confirm the benefit from the expected sustainability performance enhancement from the application of topology optimization, a test specimen needs to be manufactured at a reduced infill density. This infill density is calculated as follows:

$$
\text { New infill density }=\rho_{0}=\rho-\sigma
$$


Where, $\rho$ : optimized infill density, $\sigma:$ percentage increase in mechanical strength at known infill density.

Equation 1 will result in an infill density that will produce a topology optimized part that is at least as strong as the non-optimized part but with the sustainability performance enhancements in terms of shorter manufacturing time, lower material consumption, and lesser electrical energy consumption.

The details of confirmation experiment are discussed here. The response variables for an optimized and a non-optimized specimen is known from previous results. The infill density of the optimized specimen will be adjusted based on the percentage increase in mechanical strength. An infill density of 55\% is chosen which means that the adjusted infill density of the optimized specimen will be $55 \%$ minus $16 \%$. The experiments are caried out exactly as previously described and the results are shown in Table 12. The results conclusively indicate that topology optimization is indeed an effective strategy to reduce material consumption, manufacturing time, and electrical energy consumption. Topology optimization as a design tool allows the design engineer to maintain the mechanical performance of a part whilst reducing the material consumption, manufacturing time and electrical energy consumption. Topology optimization in FDM results in a reduced volume of the FDM part. The reduced volume along with the infill density of the part determines the effective density of the part. The present work found that topology optimization offers increased sustainability performance for a defined range of infill densities. The upper limit of this range is found to be $98 \%$. The effective density at $98 \%$ infill density reaches the physical limit for the material and therefore the mechanical performance of the part is expected to be, at best, the same as a non-optimized specimen.

Table 12. Sustainability enhancement-confirmation experiment results

\begin{tabular}{|l|c|c|c|c|c|}
\hline $\begin{array}{c}\text { Topology } \\
\text { Optimized }\end{array}$ & $\begin{array}{c}\text { Infill } \\
\text { Density } \\
{[\%]}\end{array}$ & $\begin{array}{c}\text { Mechanical } \\
\text { Strength } \\
{[\mathbf{k g}]}\end{array}$ & $\begin{array}{c}\text { Material } \\
\text { Consumption } \\
{[\mathbf{g}]}\end{array}$ & $\begin{array}{c}\text { Manufacturing } \\
\text { Time } \\
{[\mathbf{s}]}\end{array}$ & $\begin{array}{c}\text { Electrical Energy } \\
\text { Consumption } \\
{[\mathbf{W h}]}\end{array}$ \\
\hline No & 55 & 60.49 & 45.61 & 7200 & 380.01 \\
\hline Yes & 39 & 61.6 & 31.76 & 6222 & 339.3 \\
\hline
\end{tabular}

With mechanical strength as the target parameter, the percentage savings in response variables for the optimized specimens are given in Table 13. The savings listed in Table 13 are obtained due to the implementation of topology optimization as a design tool. The material consumption response variable shows greater savings than the other response variables. The percentage values are calculated for the specific specimen used in the present work with the specified machine parameters listed in Table 1. These values are expected to differ based on part geometry on machine parameters.

Table 13. Percentage savings from optimized input parameters

\begin{tabular}{|c|c|c|}
\hline $\begin{array}{c}\text { Material Consumption } \\
\text { Savings }\end{array}$ & $\begin{array}{c}\text { Manufacturing Time } \\
\text { Savings }\end{array}$ & $\begin{array}{c}\text { Electrical Energy } \\
\text { Consumption Savings }\end{array}$ \\
\hline $30.37 \%$ & $13.58 \%$ & $10.71 \%$ \\
\hline
\end{tabular}




\section{Conclusions}

The present research studied the effect of topology optimization strategy for anisotropic materials which are used to make FDM parts. This research determined that there exists a range of infill densities, 28 -to $95 \%$, for a material retention percentage of $60 \%$ at which the electrical energy consumption, manufacturing time and material consumption can be reduced without negatively affecting the mechanical performance. This is explained by increasing the effective density of a part in areas where higher stresses are expected, using topology optimization as a design tool. In other words, topology optimized material infill has reduced energy and material consumption and minimized part manufacturing time with improved mechanical strength. Although it is for parts that have been topologically optimized with a material retention rate of $60 \%$ and an infill density higher than $28 \%$ and lower than $95 \%$. The uniqueness of the present work is summarized as the quantification of the increase in sustainability performance in additive manufacturing and the implementation of topology optimization as a design tool to optimize the mechanical performance whilst reducing manufacturing cost. Previously, the notion was that the savings offered by topology optimization are without taking into account the effects of complex geometries on manufacturing time, material consumption and electrical energy consumption. The present work illustrates that any cost reductions are highly dependent on machine parameters and part geometry. The following achievement of this work highlights the sustainability enhancement in FDM, without compromising on mechanical performance:

- Material consumption savings of $30.37 \%$

- Manufacturing time savings of $13.58 \%$

- Electrical energy consumption savings of $10.71 \%$

Overall, it can be concluded that topology optimization, which can be applied using a basic FDM machine, is a good technique to achieve sustainability in additive manufacturing by improving the mechanical strength of a part that is not manufactured at an infill density greater than $98 \%$ or below $28 \%$.

\section{References}

[1] Wegner, A., Harder, R., Witt, G., Drumme, D. (2015). Determination of Optimal Processing Conditions for the Production of Polyamide 11 Parts using the laser sintering process. International Journal of Recent Contributions from Engineering, Science \& IT , 3(1): 5-12. https://doi.org/10.3991/ijes.v3i1.4249

[2] Drummer, D., Harder, R., Witt, G., Wegner, A., Wudy, K., Drexler, M. (2015). Long-term Properties of Laser Sintered Parts of Polyamide 12. International Journal of Engineering Pedagogy, 3 (1): 20:27. https://doi.org/10.3991/ijes.v3i1.4289

[3] Zhao, M., Drummer, D., Wudy, K., Drexler, M. (2015). Sintering Study of Polyamide 12 Particles for Selective Laser Melting. International Journal of Engineering Pedagogy, 3(1): 28:33. https://doi.org/10.3991/ijes.v3i1.4290

[4] Chua, C. K., Leong, K. F., Lim, C. S. (2010). Rapid prototying: principles and applications. World Scientific Publishing Co Pte Ltd. https://doi.org/10.1142/6665 
[5] Peng, T. (2016). Analysis of energy utilization in 3D printing processes. Procedia CIRP, 40: 62-67. https://doi.org/10.1016/j.procir.2016.01.055

[6] Gibson, I., Rosen, D., Stucker, B. (2014). Additive Manufacturing Technologies: 3D Printing, Rapid Prototyping, and Direct Digital. Springer. https://doi.org/10.1007/978-1-4939-2113-3

[7] Belter, J. T., Dollar, A. M. (2015). Strengthening of 3D Printed Fused Deposition Manufactured Parts Using the Fill Compositing Technique. PLoS ONE, 10 (4): e122915. https://doi .org/10.1371/journal.pone.0122915

[8] Liu, S., Li, Q., Liu, J., Chen, W., Zhang, Y. (2018). A realization method for transforming a topology optimization design into additive manufacturing structures. Engineering, 4(2): 277-285. https://doi.org/10.1016/j.eng.2017.09.002

[9] Mirzendehdel, A. M., Rankouhi, B., Suresh, K. (2018). Strength-Based Topology Optimization for Anisotropic Parts. Additive Manufacturing, 19: 104-113. https://doi.org/10.1016/j addma.2017.11.007

[10] Zhang, X., Xia, Y., Wang, J., Yang, Z., Tu, C., Wang, W. (2015). Medial axis tree - an interesting internal supporting structure for 3D ptrinting. Computer Aided Geometric Design, 35-36: 149-162. https://doi.org/10.1016/j.cagd.2015.03.012

[11] Pandey, P. M., Reddy, N. V., Dhande, S. (2003). Improvement of surface finish by staircase machining in fused deposition modelling. Journal of Materials Processing Technology, 132 (1-3): 323-331. https://doi.org/10.1016/S0924-0136(02)00953-6

[12] Boschetto, A., Bottini, L. (2015). Roughness prediction in coupled operations of fused deposition modeling and barrel finishing. Journal of Materials Processing Technology, 219: 181-192. https://doi.org/10.1016/j.jmatprotec.2014.12.021

[13] Montgomery, D.G. (2009). Design and analysis of experiments. John Willey \& Sons.

[14] Peng, T., Sun, W. (2017). Energy modeling for FDM 3D printing from a life cycle perspective. International Journal of Manufacturing Research, 12(1): 83-98. https://doi .org/10.1504/IJMR.2017.083651

[15] Espach, A., Gupta, K. (2020). Sustainability in Additive Manufacturing-A Review. 5th North American International Conference on Industrial Engineering and Operations Management, Detroit, USA, 3210-3218.

\section{$7 \quad$ Authors}

Andre Espach is pursuing MEng at the University of Johannesburg. He completed undergraduate studies at the University of Pretoria. He has over three years of engineering design and consulting experience in the fields of static structure design, submersible pump design and sustainable energy design.

Kapil Gupta is working as Associate Professor at the University of Johannesburg. Advanced machining processes, additive and sustainable manufacturing, green machining, precision engineering and gear technology are the areas of his interest. He has authored several international journal and conference articles. He is a rated researcher in Republic of South Africa and working on many international research projects.

Article submitted 2021-04-27. Resubmitted 2021-05-29. Final acceptance 2021-06-10. Final version published as submitted by the authors. 